\title{
Postfledging Survival, Movements, and Dispersal of Ring Ouzels (Turdus torquatus)
}

Author(s): Innes M. W. Sim, Sonja C. Ludwig, Murray C. Grant, Joanna L. Loughrey, Graham W. Rebecca, and Jane M. Reid

Source: The Auk, 130(1):69-77. 2013.

Published By: The American Ornithologists' Union

URL: http://www.bioone.org/doi/full/10.1525/auk.2012.12008

BioOne (www.bioone.org) is a nonprofit, online aggregation of core research in the biological, ecological, and environmental sciences. BioOne provides a sustainable online platform for over 170 journals and books published by nonprofit societies, associations, museums, institutions, and presses.

Your use of this PDF, the BioOne Web site, and all posted and associated content indicates your acceptance of BioOne's Terms of Use, available at www.bioone.org/page/terms of use.

Usage of BioOne content is strictly limited to personal, educational, and non-commercial use. Commercial inquiries or rights and permissions requests should be directed to the individual publisher as copyright holder. 


\title{
POSTFLEDGING SURVIVAL, MOVEMENTS, AND DISPERSAL OF RING OUZELS
}

\section{(TURDUS TORQUATUS)}

\author{
InNes M. W. Sim, ${ }^{1,2,4}$ Sonja C. LudWig, ${ }^{1,5}$ Murray C. Grant, ${ }^{1,6}$ Joanna L. Loughrey, ${ }^{2,6}$ \\ Graham W. Rebecca, ${ }^{3}$ and Jane M. Reid ${ }^{2}$ \\ ${ }^{1}$ Royal Society for the Protection of Birds (RSPB) Scotland, Ground Floor, 2 Lochside View, Edinburgh Park, Edinburgh, EH12 9DH, United Kingdom; \\ ${ }^{2}$ Institute of Biological \& Environmental Sciences, School of Biological Sciences, Zoology Building, University of Aberdeen, Tillydrone Avenue, \\ Aberdeen, AB24 2TZ, United Kingdom; and \\ ${ }^{3}$ RSPB Scotland, 10 Albyn Terrace, Aberdeen, AB10 1YP, United Kingdom
}

\begin{abstract}
Recent evidence suggests that avian population growth rates may be constrained by low postfledging survival. Therefore, quantifying postfledging mortality and understanding the ecological factors that influence it are fundamental for assessing the relative importance of this life-history stage for population growth and identifying the ecological drivers of population dynamics. We radiotracked 110 juvenile Ring Ouzels (Turdus torquatus), a species of high conservation concern in the United Kingdom, to test hypotheses regarding the timing and causes of postfledging mortality and to quantify the timing and magnitude of local movements and dispersal. Juveniles fledged from early-season broods had higher survival during each 4-day period over 116 days postfledging $(0.952 \pm 0.011[\mathrm{SE}])$ than juveniles fledged from late-season broods $(0.837 \pm 0.021)$. Most mortality occurred within the first 3 weeks postfledging, and predation by raptors and mammals was the main apparent cause of mortality, accounting for $59 \%$ and $27 \%$ of deaths, respectively. Juvenile survival decreased at the age of independence from parental care. Juveniles traveled increasing distances from their nests with time after fledging, and those that fledged early in the season dispersed outside the study area at significantly older ages than those that fledged late in the season. Received 20 January 2012, accepted 12 October 2012.
\end{abstract}

Key words: dispersal, juvenile, known fate, radiotracking, Ring Ouzel, survival, Turdus torquatus.

\section{Supervivencia, Movimientos y Dispersión de Turdus torquatus Después del Emplumamiento}

RESUMEN.-Evidencia reciente sugiere que las tasas de crecimiento de las poblaciones de aves podrían estar restringidas por la supervivencia después del emplumamiento. Por lo tanto, cuantificar la mortalidad posterior al emplumamiento y entender los factores ecológicos que la influencian es fundamental para establecer la importancia relativa de esta etapa de la historia de vida en el crecimiento poblacional, y para identificar los factores ecológicos que influyen en la dinámica poblacional. Rastreamos por radio a 100 individuos jóvenes de Turdus torquatus, una especie de alto interés para la conservación en el Reino Unido, para probar hipótesis relacionadas con el momento y las causas de mortalidad posterior al emplumamiento y para cuantificar el momento y magnitud de los movimientos locales y la dispersión. Los individuos que abandonaron el nido temprano en la temporada tuvieron mayor supervivencia durante cada periodo de 4 días por 116 días posteriores al emplumamiento ( $0.952 \pm 0.011$ [SE]) que los de camadas tardías $(0.837 \pm 0.021)$. La mayoría de la mortalidad se dio en las tres primeras semanas después del emplumamiento, y la depredación por aves rapaces y mamíferos fue la principal causa aparente de mortalidad. Estas causas fueron responsables del $59 \%$ y $27 \%$ de las muertes, respectivamente. La supervivencia de los jóvenes disminuyó en la edad de la independencia del cuidado parental. Los jóvenes viajaron distancias más grandes desde sus nidos con el transcurso del tiempo después del emplumamiento, y aquellos que emplumaron temprano en la temporada se dispersaron por fuera del área de estudio a edades significativamente mayores que aquellos que emplumaron tarde en la temporada.

TEMPORAL AND SPATIAL variation in prebreeding survival can have important effects on the population dynamics of mammals and birds, yet it is one of the least-studied components of vertebrate demography (Gaillard et al. 1998). Many avian studies have found that a substantial proportion of prebreeding mortality occurs during the juvenile period, defined here as the period between fledging and dispersal from the natal area some days or weeks later (e.g., Anders et al. 1997, Naef-Daenzer et al. 2001,

${ }^{4}$ E-mail: innes.sim@rspb.org.uk

${ }^{5}$ Present address: Konrad Lorenz Research Station, Fischerau 11, 4645 Gruenau, Austria.

${ }^{6}$ Present address: RPS Planning \& Development, Ocean Point One, 4th floor, 94 Ocean Drive, Edinburgh, EH6 6JH, United Kingdom.

The Auk, Vol. 130, Number 1, pages 69-77. ISSN 0004-8038, electronic ISSN 1938-4254. @ 2013 by The American Ornithologists' Union. All rights reserved. Please direct all requests for permission to photocopy or reproduce article content through the University of California Press's Rights and Permissions website, http://www.ucpressjournals. com/reprintInfo.asp. DOI: 10.1525/auk.2012.12008 
Vitz and Rodewald 2011). Population growth rate $(\lambda)$ may therefore be constrained by survival during this specific period (King et al. 2006, Yackel Adams et al. 2006). A quantification of the magnitude of, and an understanding of the ecological factors that influence, postfledging mortality is key in assessing the relative importance of this life-history stage for population growth, and for identifying ecological drivers of population dynamics and potential mitigating measures for populations of conservation concern (e.g., Anders et al. 1997, Yackel Adams et al. 2006).

A juvenile's survival may depend on its ability to locate suitable habitat for foraging and concealment from predators and, hence, on its ability to move across the landscape (e.g., Anders et al.1998, Vega Rivera et al. 1998, Vitz and Rodewald 2011). Furthermore, accurate estimation of the magnitude and causes of juvenile mortality requires measurement of juvenile movements, both within and away from the natal area (e.g., Anders et al. 1998, Vitz and Rodewald 2010, Fisher and Davis 2011). Identification of the ecological factors that constrain the juvenile life-history phase therefore requires combined measurement of the timing and causes of mortality, factors that influence survival, and the timing and magnitude of local movements and dispersal from the natal area.

Factors hypothesized to influence juvenile survival rates and the timing of mortality include predation, cessation of parental care, seasonal timing of fledging, body condition at fledging, and brood size, all of which may, in turn, interact with food abundance or availability. Adult passerines of most species lead juveniles to suitable foraging habitat and provide protection from predators for the first few weeks postfledging (Badyaev and Ghalambor 2001). Nonetheless, juveniles can be particularly vulnerable to predation during this period (e.g., King et al. 2006, Ausprey and Rodewald 2011, Hovick et al. 2011). Mortality is hypothesized to further increase when juveniles of some species become fully independent from parental care because of a temporary increase in vulnerability to starvation, predation, or both. Some empirical studies have supported this hypothesis (Sullivan 1989, Anders et al. 1997), but others have not (Kershner et al. 2004), and more data are needed to determine the relative effects of predation and cessation of parental care on juvenile mortality.

Juvenile survival is widely hypothesized to be higher for offspring that fledge early in the season, when environmental conditions may be more favorable and food more abundant (Krementz et al. 1989, Smith et al. 1989, Spear and Nur 1994, Naef-Daenzer et al. 2001, Middleton and Green 2008, Vitz and Rodewald 2011), although this is not always the case (Anders et al. 1997, Green 2001, Yackel Adams et al. 2006). Similarly, juveniles in better body condition at fledging are hypothesized to have higher postfledging survival, because they may be better able to survive periods of food shortage and, by begging and moving about less, avoid predators. Some empirical studies have supported this hypothesis (Nur 1984, Krementz et al. 1989, Smith et al. 1989, Naef-Daenzer et al. 2001, Yackel Adams et al. 2006, Vitz and Rodewald 2011), but, again, others have not (Sullivan 1989, Anders et al. 1997, Kershner et al. 2004). Finally, juvenile survival has been hypothesized to be negatively related to brood size; increased competition for limited food resources in larger broods may cause a decrease in mean nestling body condition and, thus, compromise survival of juveniles from larger broods (Nur 1984, Smith et al. 1989). Conversely, however, higher-quality parents and/or higher-quality breeding sites may be better able to support larger broods (Holmes et al. 1996), which may, in turn, lead to a positive relationship between brood size and juvenile survival (Spear and Nur 1994). In summary, there are multiple conflicting predictions regarding relationships between juvenile survival and seasonal patterns of fledging, body condition, and brood size, and, to date, no overarching patterns have been established.

The timing and ecology of juvenile movements, both before independence from parental care and during premigratory dispersal away from the natal area following independence, are even less well-quantified than variation in juvenile survival itself. As expected, distance from the natal nest increased with juvenile age (Kershner et al. 2004, Berkeley et al. 2007, Vitz and Rodewald 2010, Fisher and Davis 2011, Hovick et al. 2011). However, dispersal may occur immediately after fledglings leave the nest (Morton 1991, Lens and Dhondt 1994) in some species, whereas in others, juveniles remain near their natal nest until the start of full seasonal migration (Anders et al. 1998, Vega Rivera et al. 1998, Kershner et al. 2004), presumably using available resources to prepare for the upcoming migration or winter. Data describing the timing of movements is therefore required both to understand the ecological causes and consequences of such movements and to inform estimates of the timing and magnitude of dispersal.

The Ring Ouzel (Turdus torquatus) is a red-listed species of high conservation concern in the United Kingdom (Eaton et al. 2011). Ring Ouzel populations are declining, but the underlying mechanisms are poorly understood (Sim et al. 2010). A recent demographic study indicated that population growth rate $(\lambda)$ was most sensitive to apparent first-year survival (fledging to age 1 year), which also contributed most to observed variation in $\lambda$ (Sim et al. 2011). Additionally, most (63-68\%) estimated first-year mortality occurred in the first 5 weeks postfledging, which indicates that low juvenile survival through this specific period may substantially affect $\lambda$ (Sim et al. 2011). Understanding the timing and causes of juvenile mortality may therefore be key to devising effective population management for this species.

We used radiotracking of a large sample of juvenile Ring Ouzels to quantify the timing and causes of postfledging mortality. Radiotelemetry allows the precise location of surviving and dead individuals to be regularly determined with little bias, dispersal events to be confirmed or inferred with relatively high confidence, and specific causes of mortality to be identified. We then tested the hypotheses that juvenile survival would be higher for early- than for late-season broods, increase with improved body condition, but then decrease with increasing brood size, fledge date, and at the transition to parental independence. By continuing to track throughout the postfledging period, we quantified the timing and magnitude of local movements and dispersal from the natal area. We thus integrate factors associated with postfledging survival with quantification of the timing and magnitude of local movements and dispersal.

\section{Methods}

\section{Study Area And Species}

The Ring Ouzel is a medium-sized migratory thrush that breeds in northwest and central Europe and winters in southern Spain and North Africa (Wernham et al. 2002). We studied a population that occupies $\sim 18 \mathrm{~km}^{2}(9 \times 2 \mathrm{~km})$ of southern Glen Clunie $\left(56^{\circ} 56^{\prime} \mathrm{N}\right.$, $\left.3^{\circ} 25^{\prime} \mathrm{W}\right)$, northeast Scotland, from 2006 to 2008. Land use on the 
valley floor is mainly livestock grazing, with two small conifer plantations, but vegetation cover at higher elevations is a mosaic of heathers (Calluna vulgaris, Erica cinerea, and E. tetralix), Billberry (Vaccinium myrtillus), Crowberry (Empetrum nigrum), and rough grassland, with numerous crags, scree slopes, and gullies. The valley is managed for sport shooting of Red Grouse (Lagopus lagopus scoticus) and Red Deer (Cervus elaphus). Gamekeepers effectively eliminate predators such as Red Foxes (Vulpes vulpes) and Carrion Crows (Corvus corone), but Stoats (Mustela erminea) and Weasels (M. nivalis) were regularly seen.

In each year, we aimed to locate all Ring Ouzel breeding pairs and nesting attempts. The study area was systematically surveyed, by covering all ground to within $200 \mathrm{~m}$ of observers, every 1-2 weeks between mid-April and mid-July (Sim et al. 2011). Ring Ouzels vigorously defend the immediate vicinity of nests, but disputes outside this area are rare (Burfield 2002). In Scotland, breeding adults forage a mean distance of $197 \mathrm{~m}$ from the nest, and $95 \%$ of foraging locations were within $450 \mathrm{~m}$ (Burfield 2002). A successful breeding cycle requires 29-30 days (Burfield 2002), and British Ring Ouzels regularly make two, rarely three, breeding attempts per season (Sim et al. 2012b). "Early" and "late" pairs were defined as those that laid eggs within 30 days of the first laying date and on or after day 31, respectively, in each year (Sim et al. 2011). Egg laying was recorded directly in nests found during laying or hatching, or estimated using known relationships between chick age and wing length and mass (Burfield 2002) or by comparison with photographs of known-age nestlings. During 2006-2008, we located 56 early and 42 late nests before nestlings fledged, comprising $95 \%$ and $93 \%$ of known successful early and late nests, respectively. We located $84 \%$ of nests with eggs and $16 \%$ with nestlings. To allow individual identification, 228 nestlings (127 and 101 from early and late nests, respectively), comprising $90 \%$ of individuals known to fledge in the study area, were uniquely banded with metal and plastic color bands.

\section{Juvenile Survival and Movements}

To measure juvenile survival and movements during MaySeptember, nestlings were fitted with 1.8-g TW4 single-celled radiotransmitters (Biotrack, Wareham, United Kingdom) just prior to fledging (10-14 days posthatch), at which age brood size (the number of nestlings alive) was recorded. Transmitters were backmounted using an elastic harness with a weak cotton link, to allow tag loss prior to migration. In 2006, 22 late-brood nestlings were fitted with transmitters and appeared to fly as well as color-banded juveniles without transmitters when flushed, and dispersed over similar distances and periods as color-banded siblings. They thus showed no detrimental behavioral effects of radiotransmitters, in common with previous studies (Rae et al. 2009, Gow et al. 2011). Subsequently, a further 23 and 21 early-brood nestlings and 18 and 26 late-brood nestlings were fitted with transmitters in 2007 and 2008 , respectively (giving totals of 44 early-nest nestlings from 25 broods and 66 late-nest nestlings from 30 broods, respectively). We aimed to fit transmitters to at least one nestling from all successful broods. All nestlings in broods of 1-2 were fitted with transmitters. In broods of 3-5, nestlings were ranked according to wing length (the best predictor of nestling age; Burfield 2002), and 2-3 nestlings were selected at random according to these rankings and fitted with transmitters. Thus, transmitters were fitted to single nestlings in 7 broods, 2 nestlings in 41 broods, and 3 nestlings in 7 broods.
Juveniles with transmitters were tracked and their locations recorded every 3-4 days postfledging, until the individual was found dead, shed the transmitter, or disappeared and was assumed to have dispersed from the study area. Tracking therefore continued throughout the entire postfledging, predispersal, period. Survival estimates presented here therefore differ from those in Sim et al. (2011), in which survival was measured on a weekly basis for 5 weeks postfledging only, and in which "true" first-year survival to recruitment was back-calculated from population-wide demographic data. Individuals were tracked at different times on different tracking days. Transmitters had signal ranges of $\sim 10 \mathrm{~km}$ with direct line of sight, but more typically $2-3 \mathrm{~km}$ depending on terrain, and a battery life of $\geq 4$ months. We used Advanced Telemetry Systems (ATS; Isanti, Minnesota) scanning receivers attached to car-roof-mounted aerials to provide approximate locations. Hand-held Telonics TR-4 receivers, attached to three-element Yagi antennas, were used to visually locate each individual on foot and record their location using a Garmin global positioning system (GPS) 12 Personal Navigator. Individuals $<7$ days old postfledging usually "froze" on approach and hid in tall vegetation. However, older individuals flushed on $\sim 90 \%$ of occasions, but generally flew $<100 \mathrm{~m}$ and hid or resumed foraging. On the remaining $10 \%$ of occasions, individuals did not fly but hopped away and hid or resumed foraging nearby.

The location from which each juvenile flushed was usually recorded to the nearest $10 \mathrm{~m}$ ( $87 \%$ of locations). However, more mobile birds had their initial location estimated to the nearest $100 \mathrm{~m}$ (13\% of locations). Each located individual was observed for $\sim 15$ min to determine whether it was dependent on its parents or apparently independent. Juveniles were defined as "dependent" when at least one adult was observed within $100 \mathrm{~m}$, carrying food, or giving agitated alarm calls. Juveniles were classed as "independent" midway between the last observation when at least one parent was present and the first observation when neither parent was seen or heard. On no occasion was a juvenile observed to be dependent after having previously been classed as independent.

Each visual location was plotted onto digital 1:25,000 Ordnance Survey maps in MAPINFO PROFESSIONAL, version 6 (MapInfo, New York), and the distance from the nest calculated (excluding those apparently depredated, because the predator may have moved the dead bird). To locate juveniles that dispersed from the study area, we drove most roads within a $20-\mathrm{km}$ radius once every 2 weeks during early August to early September, using ATS scanning receivers attached to roof-mounted aerials. In addition, we made four aerial searches (two each in mid- to late August 2006 and 2007) within a radius of $\sim 40 \mathrm{~km}$, using a fixed-wing aircraft. Any birds detected on these more extensive searches were followed up by searches on foot to confirm their precise location.

\section{Causes and Timing of Mortality}

Remains of juveniles that were found were examined to determine the most likely cause of death. Individuals found in raptor nests, or elsewhere with plucked feathers and bent aerials, were assumed to have been killed by raptors, whereas those located underground in tunnels, under boulders, or in the open with bitten feathers and unbent aerials were assumed to have been killed by mammals (Thirgood et al. 1998). Juveniles with no apparent injuries that were found close to nests or in rivers were assumed to have died from exposure and drowning, respectively, and cases 
of accidental mortality were assigned to the most likely cause of death (see below). Because juvenile location and status (deadalive) was checked at 3- to 4-day intervals, the timing of mortality was also accurate to within 3-4 days.

\section{Body Condition}

To test whether juvenile survival, or movements within or away from the study area, varied with nestling body condition, we measured a body condition index $(\mathrm{BCI})$ as the residual of a regression of body mass on wing length ${ }^{3}$ (body mass $=67.3+0.00001^{*}$ wing length ${ }^{3} ; r^{2}=0.06$; Genevois and Bretagnolle 1994). We measured wing length (maximum chord to the nearest $1 \mathrm{~mm}$ ) and body mass (to the nearest $0.5 \mathrm{~g}$, using a Pesola balance) for all nestlings aged 10-14 (mean $=12)$ days posthatch (Burfield 2002).

\section{Statistical Analysis}

Survival analysis.-We examined variation in juvenile survival over 116 days postfledging $(29 \times 4$-day periods, from 21 May to 14 September), after which no individuals fitted with radiotransmitters remained within the study area, using three different sets of known-fate models in Program MARK, version 5.1 (White and Burnham 1999). Known-fate models assume (1) that the fate of each individual is known with certainty (although "missing" individuals can be censored during the period they are not found, and re-enter the data set when they are relocated) and (2) that the fates of individuals are independent. When individual survival probabilities are not independent, estimated effects are unbiased, but variances are biased downward because of extrabinomial variation or overdispersion of the data (Tsia et al. 1999). Biologically, overdispersion might be expected if the fates of different brood members covary. We tested for significant violation of the assumption of independence by estimating overdispersion $(\hat{c})$ as $\chi^{2} / \mathrm{df}$, where $\chi^{2}$ is the summation of partial chi-square values ([observed - expected $]^{2} /[$ expected]) calculated for each possible outcome of losses within tagged brood sizes of 1,2 , or 3 young (9 possible outcomes). Expected values were calculated as $(n / r) p^{r}(1-p)^{n-r}$, where $n$ is brood size, $r$ is the number of young surviving to independence, and $p$ is the survival rate between fledging and independence (Wiens et al. 2006). There was no evidence of overdispersion $\left(\chi^{2}=11.17, \mathrm{df}=\right.$ $8, P=0.19)$. Individual fates were therefore treated as independent. Five individuals were temporarily censored for up to two consecutive 4-day periods for which they were unobserved before being relocated.

Candidate models were selected following examination of the literature and were designed to test a priori hypotheses (Table $\mathrm{S} 1$, supplementary material with the online version of this article; see Acknowledgments). The first set of models tested for effects of fixed factors year $(2006,2007$, or 2008) and brood season (early or late), and covariates brood size (mean $=3.45 \pm 0.07$, range: $1-5$ ) and $\mathrm{BCI}$ (mean $=0.00 \pm 0.37 \mathrm{~g}$, range: -11.87 to $8.77 \mathrm{~g}$ ), on juvenile survival. In this set of models, each juvenile encounter history began on its specific fledging date. We first tested the relative support for models in which survival was constant or varied across all 29 four-day periods. We then tested for effects on survival of the above covariates and factors on their own, when added to one another and including all possible two-way interactions.
The second and third sets of models tested for effects of age on survival, so fledging date was classified as day 1 for each juvenile's encounter history. The second set of models tested for effects of $\mathrm{BCI}$ through the first 4, 8, and 12 days postfledging, on survival of early, late, and all broods. The third set of models tested for effects of independence from parents on survival of early, late, and all broods. Individuals were included in this analysis up until their last recorded location within the study area (i.e., they were rightcensored after apparently dispersing). The saturated models fitted the data perfectly, and there is no goodness-of-fit test for such data (Cooch and White 2008).

Movement analysis.-We wished to test for an effect of distance moved by juveniles by 26 days of age (the oldest age at which all juveniles were still dependent on their parents) on survival; however, it was not possible to model the effect of the time-varying covariate distance moved. Therefore, we modeled the effects of year, brood season (early vs. late), brood size, and BCI on (1) the distance juveniles moved from their nest by 26 days of age and (2) their age at assumed dispersal out of the study area. Both response variables were $\log _{10}$ transformed to normalize their distributions, and breeding site was specified as a random effect to account for potential non-independence of juveniles fledging from the same site in different years. We tested for effects on these two response variables of the above covariates and factors on their own, when added to one another, and including all possible two-way interactions.

Akaike's information criterion adjusted for small sample size ( $\mathrm{AIC}_{\mathrm{C}}$ ) was used for all the above models to identify the bestsupported model that included the parameters of interest (Burnham and Anderson 2002). The model with the lowest $\mathrm{AIC}_{\mathrm{c}}$ was judged the best-supported model. When differences in $\mathrm{AIC}_{\mathrm{c}}\left(\Delta \mathrm{AIC}_{\mathrm{c}}\right)$ scores between models were $<2.0$, models were considered statistically indistinguishable. However, although models with $\Delta \mathrm{AIC} \geq 2.0$ and $\leq 7.0$ were considered to have less support, they may still offer insight into observed patterns (Burnham and Anderson 2002).

Because some models included two-way interactions, averaging across main effects within model sets was inappropriate. In the first survival model and the two movement-analysis models, brood season and fledging date were highly correlated (survival model: $r=0.92$, distance from nest model: $r=0.92$, age at dispersal model: $r=0.90$; all $P<0.0001)$. Because there was greater support for models with brood season, as opposed to fledging date (or fledging date ${ }^{2}$ ), as a univariate predictor, fledging date and fledging date ${ }^{2}$ were not considered further. Means are presented $\pm \mathrm{SE}$ unless otherwise stated.

\section{Results}

Variation in juvenile survival.-The best-supported model within the first set indicated that juvenile survival of early-season broods was higher during each 4-day period over 116 days postfledging $(0.952 \pm 0.011)$ than that of late-season broods $(0.837 \pm 0.021$; Table 1 and Fig. 1; Table S2, supplementary material with the online version of this article; see Acknowledgments). However, early-season juveniles were tracked for much longer than late-season juveniles. Survival probabilities calculated over equivalent 44-day periods postfledging (when $\geq 5$ individuals from both groups were tracked; Fig. 1) were $0.942 \pm 0.013$ and $0.834 \pm 0.022$ for early- and lateseason juveniles, respectively. 
TABLE 1. Known-fate models used to estimate juvenile survival during 116 ( $29 \times 4$-day periods) days postfledging, in relation to year (yr; 2006, 2007, or 2008), brood season (br; early or late), brood size (bs), and body condition index $(\mathrm{BCl})$ and with full time dependence (time) for Ring Ouzels in northeast Scotland, 2006-2008. For models in this table, and in Tables 3 and 4, asterisks indicate main effects plus two-way interactions. For all models, only those with $\Delta \mathrm{AIC}_{\mathrm{c}} \leq 7$ are shown, and the best-supported model is indicated in bold. Regression coefficients of estimated linear change $(\beta \pm S E)$ are provided for models that include covariates. $k=$ number of parameters and $w_{i}=\mathrm{AIC}_{\mathrm{c}}$ weight.

\begin{tabular}{lcccccc}
\hline Model & $k$ & $\mathrm{AIC}_{\mathrm{c}}$ & $\Delta \mathrm{AIC}_{\mathrm{c}}$ & $w_{i}$ & Deviance & $\beta \pm \mathrm{SE}$ \\
\hline $\boldsymbol{\varphi}(\mathbf{b r})$ & $\mathbf{2}$ & $\mathbf{4 3 7 . 1 0}$ & $\mathbf{0 . 0}$ & $\mathbf{0 . 2 5 3}$ & $\mathbf{4 3 3 . 0 8}$ & \\
$\varphi(\mathrm{br}+\mathrm{bs})$ & 3 & 437.46 & 0.4 & 0.211 & 431.42 & $0.22 \pm 0.17$ \\
$\varphi(\mathrm{br}+\mathrm{BCl})$ & 3 & 437.88 & 0.8 & 0.171 & 431.84 & $0.04 \pm 0.03$ \\
$\varphi(\mathrm{br}+\mathrm{yr})$ & 4 & 438.59 & 1.5 & 0.120 & 430.54 & \\
$\varphi(\mathrm{br} * \mathrm{yr})$ & 5 & 439.10 & 2.0 & 0.093 & 429.02 & \\
$\varphi(\mathrm{br} * \mathrm{bs})$ & 4 & 439.15 & 2.1 & 0.090 & 431.10 & \\
$\varphi(\mathrm{br} * \mathrm{BCl})$ & 4 & 439.89 & 2.8 & 0.063 & 431.83 & \\
\hline
\end{tabular}

Five other models were moderately well supported $\left(\triangle \mathrm{AIC} \mathrm{C}_{\mathrm{c}}=\right.$ 0.4-2.1), including positive effects of brood size and BCI, and twoway interactions between brood season and year and between brood season and brood size (Tables 1 and S2). Survival was similar for early broods in 2007 and 2008, and for late broods in 2006 and 2007, but late-brood survival in 2008 was considerably lower. In addition, the relationship between brood-season survival and brood size was stronger for early than for late broods.

The best-supported model within the second set indicated that both early- and late-brood juvenile survival for the first 8 days postfledging were positively associated with higher BCI at fledging (Table 2; Table S3, supplementary material with the online version of this article; see Acknowledgments). However, five more models were moderately well supported $\left(\Delta \mathrm{AIC}_{\mathrm{c}}=\right.$ 0.2-1.6), including positive effects of BCI on survival of early and late broods for 12 days, on late broods only for 4,8 , and 12 days postfledging, and brood-specific survival without an additional effect of BCI (Tables 2 and S3). However, in all models in which BCI was included as a covariate, estimated effects of $\mathrm{BCI}$ at fledging on both early- and late-brood juvenile survival were relatively small, and 95\% confidence intervals overlapped zero (Tables 2 and S3). Indeed, the most parsimonious model

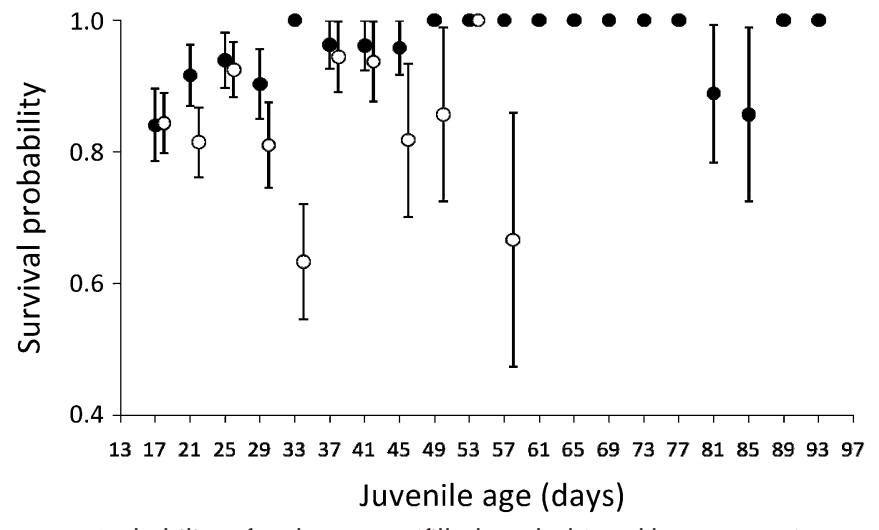

FIG. 1. Probability of early-season (filled symbols) and late-season (open symbols) juvenile survival $( \pm S E)$ in 4-day periods (e.g., figure presented for age 17 indicates survival during 14-17 days), during 2006-2008, in Ring Ouzels in northeast Scotland. Data are presented only for periods in which $\geq 5$ juveniles were being tracked (i.e., 80 days for early- and 44 days for late-season juveniles).

in the set, that which distinguished simply between early and late broods (Table 2, model 5), performed as well as models that included BCI.

The best-supported model within the third set indicated that late-brood juvenile survival decreased at independence (26-33 days), from $0.867 \pm 0.022$ to $0.731 \pm 0.054$ (Tables 3 and SI 4; Fig. 1). However, a model indicating a decrease in both early-brood (from $0.952 \pm 0.011$ to $0.949 \pm 0.029)$ and late-brood survival at independence was moderately well supported $\left(\Delta \mathrm{AIC} \mathrm{c}_{\mathrm{c}}=2.0\right.$; Tables 3 and SI 4; Fig. 1). Early broods became independent at a marginally significantly older age ( $32 \pm 1$ days) than late broods (30 \pm 1 days; $\left.\chi^{2}=3.98, P=0.05\right)$; there was no significant effect of year $\left(\chi^{2}=0.53\right.$, $P=0.75)$ or a two-way interaction between year and brood season $\left(\chi^{2}<0.01, P=0.99\right)$.

Causes and timing of mortality.-Of the 110 juveniles fitted with transmitters, 71 (64.6\%) were found dead, 32 (29.1\%) were lost track of and assumed to have dispersed outside the study area, five (4.5\%) shed their transmitters within the study area, and two (1.8\%) transmitters stopped working prematurely (juveniles could still be identified by individual color bands). Of the 71 found dead, $42(59.2 \%)$ and 19 (26.8\%) were killed by raptors and mammals, respectively. A further six (8.4\%), two (2.8\%), and two (2.8\%) died of

TABLE 2. Known-fate models used to test whether juvenile survival during 116 days postfledging varied in relation to whether an individual was from an early-season (e) or a late-season (l) brood, plus additive effects of body condition index (BCl) on survival to 4 (BCl 14-17), 8 (BCl 14-21), and 12 (BCl 14-25) days postfledging, for Ring Ouzels in northeast Scotland, 2006-2008. $k=$ number of parameters and $w_{i}=\mathrm{AIC}_{\mathrm{c}}$ weight.

\begin{tabular}{|c|c|c|c|c|c|c|c|}
\hline Model & $k$ & $\mathrm{AIC}_{\mathrm{c}}$ & $\Delta \mathrm{AIC}_{\mathrm{c}}$ & $w_{i}$ & Deviance & e $\beta \pm \mathrm{SE}$ & $\mathrm{I} \beta \pm \mathrm{SE}$ \\
\hline$\varphi(e+B C I 14-21, I+B C I 14-21)$ & 3 & 436.15 & 0.0 & 0.184 & 430.12 & $0.10 \pm 0.06$ & $0.10 \pm 0.06$ \\
\hline$\varphi(\mathrm{e} ., \mathrm{I}+\mathrm{BCl} 14-21)$ & 3 & 436.31 & 0.2 & 0.171 & 430.28 & - & $0.10 \pm 0.06$ \\
\hline$\varphi(\mathrm{e}+\mathrm{BCl} 14-25, \mathrm{I}+\mathrm{BCl} 14-25)$ & 3 & 436.52 & 0.4 & 0.153 & 430.49 & $0.08 \pm 0.05$ & $0.08 \pm 0.05$ \\
\hline$\varphi(\mathrm{e} ., \mathrm{I}+\mathrm{BCl} 14-25)$ & 3 & 436.53 & 0.4 & 0.153 & 430.50 & - & $0.08 \pm 0.05$ \\
\hline$\varphi($ e., l. $)$ & 2 & 437.10 & 0.9 & 0.115 & 433.08 & - & - \\
\hline$\varphi(\mathrm{e} ., \mathrm{I}+\mathrm{BCl} 14-17)$ & 3 & 437.78 & 1.6 & 0.082 & 431.75 & - & $0.09 \pm 0.08$ \\
\hline$\varphi(\mathrm{e}+\mathrm{BCl} 14-17, \mathrm{I}+\mathrm{BCl} 14-17)$ & 3 & 438.38 & 2.2 & 0.061 & 432.35 & $0.07 \pm 0.07$ & $0.07 \pm 0.07$ \\
\hline$\varphi(\mathrm{e}+\mathrm{BCl} 14-17, \mathrm{I})$. & 3 & 438.81 & 2.7 & 0.050 & 432.77 & $-0.10 \pm 0.18$ & - \\
\hline$\varphi(e+B C l 14-21$, I. $)$ & 3 & 438.91 & 2.8 & 0.047 & 432.87 & $0.07 \pm 0.15$ & - \\
\hline$\varphi(\mathrm{e}+\mathrm{BCl} 14-25, \mathrm{I})$. & 3 & 439.00 & 2.8 & 0.045 & 432.96 & $0.04 \pm 0.12$ & - \\
\hline
\end{tabular}


TABLE 3. Known-fate models used to test whether early-brood (e) or latebrood (I) juvenile survival during 116 days postfledging changed markedly at the approximate age of independence (26-33 days of age) in Ring Ouzels in northeast Scotland, 2006-2008. For example, for early broods: e. and $\mathrm{e}^{* 26-33}=$ constant survival and marked change in survival at 2633 days. $k=$ number of parameters and $w_{i}=\mathrm{AIC}_{\mathrm{c}}$ weight.

\begin{tabular}{lccccc}
\hline Model & $k$ & $\mathrm{AIC}_{\mathrm{c}}$ & $\Delta \mathrm{AIC}_{\mathrm{c}}$ & $w_{i}$ & Deviance \\
\hline$\varphi(\mathbf{e . ,}$ I*26-33) & $\mathbf{3}$ & $\mathbf{4 3 2 . 7 2}$ & $\mathbf{0 . 0}$ & $\mathbf{0 . 6 5 9}$ & $\mathbf{4 2 6 . 6 8}$ \\
$\varphi\left(\mathrm{e}^{*} 26-33\right.$, I*26-33) & 4 & 434.73 & 2.0 & 0.241 & 426.67 \\
$\varphi(\mathrm{e}, \mathrm{I})$. & 2 & 437.10 & 4.4 & 0.073 & 433.08 \\
$\varphi\left(\mathrm{e}^{*} 26-33\right.$, I. $)$ & 3 & 439.10 & 6.4 & 0.027 & 433.07 \\
\hline
\end{tabular}

exposure, drowning, and accidental deaths (one each trampled by a deer and strangled by its harness), respectively (Fig. 2).

The majority (30) of deaths by raptors could not be attributed to a specific species. However, the remains of 12 juveniles and/or their radiotransmitters were found in, or within $100 \mathrm{~m}$ of, Buzzard (Buteo buteo; $n=8$ ), Eurasian Kestrel (Falco tinnunculus; $n=3$ ), and Eurasian Sparrowhawk (Acccipiter nisus; $n=$ 1) nests, which strongly suggests that these were the predators. The 19 deaths by mammals could not be attributed to a specific species. However, a minimum of 12 (63\%) were likely killed by mustelids (Stoats and Weasels), because they were found in situations inaccessible to Red Foxes, such as small holes or deep in boulder scree.

A smaller proportion of early-brood $(18 / 44,41 \%)$ than of late-brood $(43 / 66,65 \%)$ juveniles was depredated $\left(\chi^{2}=5.34\right.$, $P=0.02)$. Mammals were the main predator of juveniles during the first 4 days postfledging $(8 / 11,73 \%)$, with raptors the main predator during the following 28 days postfledging (34/43, 79\%; Fig. S1, supplementary material with the online version of this article; see Acknowledgments). Mortality, apparently from exposure, drowning, and accident, occurred during the first 8 days postfledging (Fig. 2).

Juvenile movements and dispersal.-Within the study area, both early- and late-brood juveniles traveled increasingly far from their nests as they aged (Fig. 3). Early-brood juveniles moved median distances of $110 \mathrm{~m}$ (range: $44-463, n=23$ ) by age 18 days, $321 \mathrm{~m}$ (range: $81-1,323, n=21$ ) by 26 days, and 2,627 $\mathrm{m}$ (range:

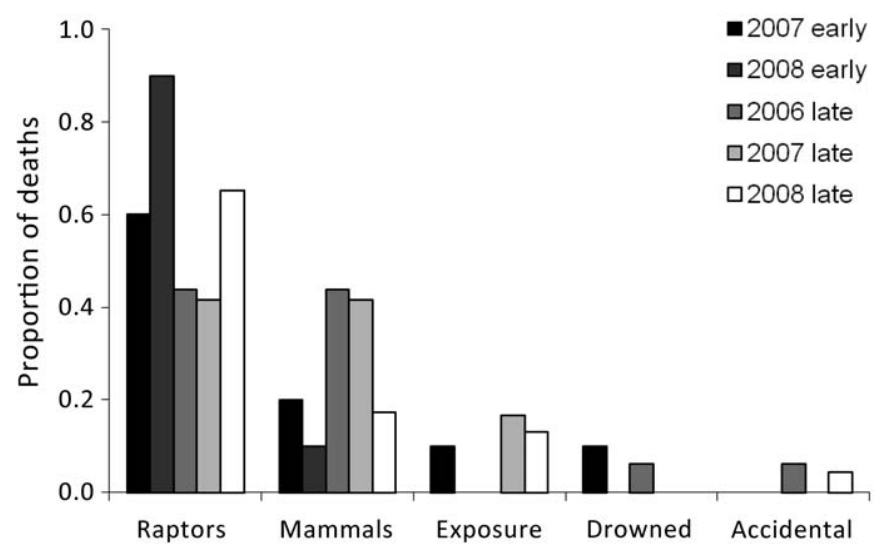

FIG. 2. Apparent causes of mortality for 71 juvenile Ring Ouzels fledged in early- or late-season broods and fitted with radiotransmitters during 2006-2008 in northeast Scotland.

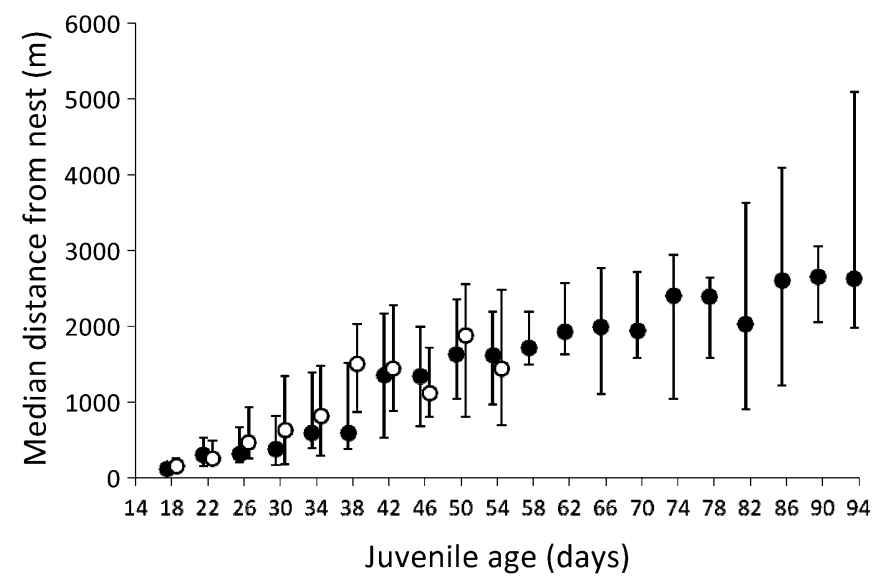

FIG. 3. Relationship between early-season (filled symbols) and lateseason (open symbols) juvenile age and median distance ( \pm first and third quartiles) found from the nest, within the study area, in 4-day periods during 2006-2008, in Ring Ouzels in northeast Scotland. Data are presented only for periods in which $\geq 5$ individuals from early- or late-season broods were monitored.

$1,547-5,776, n=5$ ) by 94 days (Fig. 3). Late-brood juveniles moved median distances of $150 \mathrm{~m}$ (range: $25-913, n=27$ ) by age 18 days, and $471 \mathrm{~m}$ (range: $86-1,843, n=24$ ) by 26 days (Fig. 3 ).

The best-supported model testing for hypothesized effects on distance moved by individuals by age 26 days indicated a twoway interaction between year and brood size (Table 4; Table S5, supplementary material with the online version of this article; see Acknowledgments). There was a positive association between distance moved and brood size in 2006 and 2008, but a negative association in 2007. However, four more models were moderately well supported $\left(\triangle \mathrm{AIC}_{\mathrm{c}}=0.6-2.1\right)$, including a two-way interaction between year and brood season, positive effects of brood season and negative effects of BCI, and their additive effects (Tables 4 and S5). Only late broods were fitted with transmitters in 2006 and there were positive, and weak negative, associations between

TABLE 4. Models testing for variation in $\log _{10}$ distance from the nest $(\mathrm{m})$ moved by juveniles by age 26 days (the oldest age at which all juveniles were still dependent on their parents) in relation to year (yr), brood season (br), brood size (bs), and body condition index (BCl) in Ring Ouzels in northeast Scotland, 2006-2008. $k=$ number of parameters and $w_{i}=\mathrm{AIC}_{\mathrm{C}}$ weight.

\begin{tabular}{lcccccc}
\hline Model & $k$ & $\mathrm{AIC}_{\mathrm{c}}$ & $\Delta \mathrm{AIC}_{\mathrm{c}}$ & $w_{i}$ & Deviance & $\beta \pm \mathrm{SE}$ \\
\hline $\mathbf{y r}^{*} \mathbf{b s}$ & $\mathbf{5}$ & $\mathbf{6 3 . 7 4}$ & $\mathbf{0 . 0}$ & $\mathbf{0 . 2 6 9}$ & $\mathbf{1 2 3 . 3 4}$ & \\
$\mathrm{yr}{ }^{*} \mathrm{br}$ & 5 & 64.37 & 0.6 & 0.196 & 124.60 & \\
$\mathrm{Br}$ & 2 & 64.46 & 0.7 & 0.187 & 124.38 & \\
$\mathrm{br}+\mathrm{BCl}$ & 3 & 65.77 & 2.0 & 0.097 & 127.40 & $-0.03 \pm 0.01$ \\
$\mathrm{BCl}$ & 2 & 65.79 & 2.1 & 0.096 & 127.44 & $-0.03 \pm 0.01$ \\
$\mathrm{br}+\mathrm{bs}$ & 3 & 67.82 & 4.1 & 0.035 & 131.50 & $-0.01 \pm 0.07$ \\
$\mathrm{Bs}$ & 2 & 68.13 & 4.4 & 0.030 & 132.12 & $-0.04 \pm 0.07$ \\
$\mathrm{yr}+\mathrm{br}$ & 4 & 68.58 & 4.8 & 0.024 & 133.00 & \\
$\mathrm{Yr}$ & 3 & 69.19 & 5.5 & 0.018 & 134.24 & \\
$\mathrm{bs}+\mathrm{BCl}$ & 3 & 69.37 & 5.6 & 0.016 & 134.60 & $-0.02 \pm 0.06(\mathrm{bs})$ \\
& & & & & & $-0.03 \pm 0.01(\mathrm{BCl})$ \\
$\mathrm{br} * \mathrm{bs}$ & 4 & 69.82 & 6.1 & 0.013 & 135.50 & \\
$\mathrm{yr}+\mathrm{BCl}$ & 4 & 70.50 & 6.8 & 0.009 & 136.86 & $-0.03 \pm 0.01$ \\
\hline
\end{tabular}


TABLE 5. Model testing for variation in $\log _{10}$ age at assumed dispersal outside the study area, in relation to year (yr), brood season (br), brood size (bs), and body condition index ( $\mathrm{BCl})$, for Ring Ouzels in northeast Scotland, 2006-2008. $k=$ number of parameters and $w_{i}=\mathrm{AIC}_{\mathrm{c}}$ weight.

\begin{tabular}{lcccccc}
\hline Model & $k$ & $\mathrm{AIC}_{\mathrm{c}}$ & $\Delta \mathrm{AIC}_{\mathrm{c}}$ & $w_{i}$ & Deviance & $\beta \pm \mathrm{SE}$ \\
\hline $\mathbf{b r}$ & $\mathbf{2}$ & $\mathbf{- 3 6 . 4 6}$ & $\mathbf{0 . 0}$ & $\mathbf{0 . 7 8 8}$ & $\mathbf{- 7 7 . 2 2}$ & \\
$\mathrm{br}+\mathrm{bs}$ & 3 & -32.40 & 4.1 & 0.104 & -69.10 & $0.03 \pm 0.03$ \\
$\mathrm{yr}+\mathrm{br}$ & 4 & -29.78 & 6.7 & 0.028 & -63.86 & \\
\hline
\end{tabular}

distance moved and brood season in 2007 and 2008, respectively. Clearly, multiple factors are associated with the distance from the nest moved by this age, and these apparently vary among years. All juveniles were independent by 38 days of age.

The best-supported model testing for effects of various factors on age of dispersal outside the study area indicated that early-season juveniles dispersed outside the study area at a significantly older age than-late season juveniles (Table 5; Table S6, supplementary material with the online version of this article; see Acknowledgments). In 2006, four late-brood juveniles, aged 46-66 days, were located $6.9-15.5 \mathrm{~km}$ to the north (2) and west (2) of the study area, and in 2007 two late-brood juveniles, aged 44 and 62 days, were located $6.1 \mathrm{~km}$ to the north and $13.6 \mathrm{~km}$ to the south of the study area, respectively. No juveniles were found during searches outside the study area in 2008.

\section{Discussion}

Our radiotracking of 110 juvenile Ring Ouzels for up to 116 days postfledging constitutes one of the largest and longest passerine tracking studies to date. Juvenile Ring Ouzels from early broods were more likely to survive than those from late broods, with predation being the main apparent cause of mortality. Survival of juveniles, particularly those from late broods, temporarily decreased at the age of independence. Juveniles traveled increasingly far from their nests with time since fledging, and individuals that fledged from larger broods later in the season and with lower body condition tended to move farthest while dependent on their parents. Juveniles that fledged early in the season dispersed outside the study area at a significantly older age than those that fledged later on.

Variation in juvenile survival with brood season and brood size.-Juvenile Ring Ouzels that fledged from early broods had higher survival probabilities than those that fledged from late broods, as observed in European Starlings (Sturnus vulgaris; Krementz et al. 1989), Western Gulls (Larus occidentalis; Spear and Nur 1994), Great Tits (Parus major; Smith et al. 1989), Coal Tits (Periparus ater; Naef-Daenzer et al. 2001), American Dippers (Cinclus mexicanus; Middleton and Green 2008), and Ovenbirds (Seiurus aurocapilla; Vitz and Rodewald 2011). However, Anders et al. (1997) found no association between juvenile survival and fledging date in Wood Thrushes (Hylocichla mustelina); and juvenile Brown Thornbill (Acanthiza pusilla; Green 2001), Lark Bunting (Calamospiza melanocorys; Yackel Adams et al. 2006), and Worm-eating Warbler (Helmitheros vermivorum; Vitz and Rodewald 2011) survival increased as the season progressed.
Many factors (e.g., food supply, predation rates, and environmental conditions) likely influence the survival of fledglings (e.g., Green and Cockburn 2001, Naef-Daenzer et al. 2001, Yackel Adams et al. 2006, Vitz and Rodewald 2011). In Ring Ouzels, higher survival of early-season juveniles than of late-season individuals was apparently associated with reduced predation rates, rather than increased food abundance (Sim et al. 2012a).

We also found a positive association between brood size and juvenile survival. This contrasts with the negative relationship observed in two studies, where increased competition for limited food resources in larger broods caused a decrease in mean nestling body condition in Blue Tits (Cyanistes caeruleus; Nur 1984) and Great Tits (Smith et al. 1989) and, thus, reduced survival of juveniles from broods of larger size. However, brood size and subsequent juvenile survival may be higher for individuals reared by higher-quality parents and/or in higher-quality breeding sites (Holmes et al. 1996, Green 2001). Indeed, a positive relationship between brood size and juvenile survival was found in Western Gulls, with the advantage of hatching into a large brood considered to reflect a direct effect (competitive abilities may covary positively with brood size due to interaction between siblings), and/or an indirect effect (parental quality; Spear and Nur 1994). In Ring Ouzels, the higher survival of juveniles from larger broods most likely reflects positive effects of parental and/or foraging habitat quality.

Variation with body condition.-Low food availability is one possible cause of low juvenile survival, with effects being either direct (through starvation) or indirect. However, we found no compelling evidence that postfledging survival varied with nestling body condition in Ring Ouzels. Although six previous studies found that juvenile survival was positively related to nestling condition (Nur 1984, Krementz et al. 1989, Smith et al. 1989, NaefDaenzer et al. 2001, Yackel Adams et al. 2006, Vitz and Rodewald 2011), three others found no such effect (Sullivan 1989, Anders et al. 1997, Kershner et al. 2004). These discrepancies may indicate that nestling condition influences survival only during periods of environmental stress (Krementz et al. 1989).

Predation.-Predation was the main apparent cause of juvenile mortality in Ring Ouzels, with most deaths occurring within 5 weeks postfledging. These results concur with those of several previous studies in which high predation rates occurred in the first few weeks postfledging (e.g., Naef-Daenzer et al. 2001, Yackel Adams et al. 2006, Vitz and Rodewald 2011). Because juvenile Ring Ouzels have limited flying ability during 4-8 days postfledging, they are then particularly vulnerable to mammalian predators. After this age, juveniles were capable of short flights, and raptors were the main predators thereafter. Gamekeepers legally cull mustelids, Red Foxes, and Carrion Crows, but all raptor species are protected by law and cannot be legally culled (Tucker and Heath 1994). Because gamekeepers employ similar methods of pest control across large parts of upland Britain, and thus throughout much of the British Ring Ouzel's breeding range (Gibbons et al. 1993, 1995), the number and variety of predators found in Glen Clunie are likely to broadly reflect those found elsewhere in upland Britain.

The switch from mammal-dominated predation early in the postfledging period to raptor-dominated predation later on has previously been shown in Ovenbirds and Worm-eating Warblers 
(Vitz 2008). Avian predators were considered the main cause of mortality in juvenile Wood Thrushes (Anders et al. 1997, Schmidt et al. 2008) and Sprague's Pipits (Anthus spragueii; Fisher and Davis 2011), whereas mammals were considered the main predators of Lark Buntings (Yackel Adams et al. 2006).

Independence from parental care.-We found a temporary reduction in juvenile survival at the age of parental independence (26-33 days), especially in late broods (Fig. 1). At this age, juveniles were no longer attended by their parents, had to forage for themselves, and were, thus, potentially more vulnerable to predation. Similar peaks in mortality at independence have previously been observed in Yellow-eyed Juncos (Junco phaeonotus; Sullivan 1989) and Wood Thrushes (Anders et al. 1997), but not in Eastern Meadowlarks (Sturnella magna; Kershner et al. 2004; Table 1). This second peak in juvenile Ring Ouzel mortality occurs mainly in late broods, coinciding with the period when predation pressure from raptors with recently fledged young is highest. Naef-Daenzer et al. (2001) also noted higher predation rates later in the season, causing reduced survival of fledgling Great and Coal tits.

Juvenile movements and dispersal.-Juvenile Ring Ouzels traveled increasingly far from their nests with increasing time since fledging (Fig. 2), in common with other passerines (Kershner et al. 2004, Berkeley et al. 2007, Vitz and Rodewald 2010, Fisher and Davis 2011). Clearly, there was substantial among-year variation in the distance moved by juveniles by age 26 days, possibly reflecting differences in the availability of invertebrate prey (Burfield 2002), the abundance of Bilberries or Crowberries (both important late summer food sources; Watson 1972, Sim et al. 2012a), weather conditions, or the abundance of predators.

Of the 32 juveniles that were considered to have dispersed outside the study area, 23 had moved unusually long distances $(1.3-5.0 \mathrm{~km})$ from their nest sites during the 10 days preceding their estimated dispersal date ( 6 were subsequently located outside the study area). Of the remaining nine, two were also subsequently located outside the study area. This suggests that the majority of juveniles that we lost track of did in fact disperse, rather than experience transmitter failure. Similar movements during 3-7 days prior to natal area dispersal have been observed in Wood Thrushes (Anders et al. 1997, Vega Rivera et al. 1998).

Juvenile Ring Ouzels from late broods dispersed outside the study area at an earlier age than those from early broods, which is similar to a pattern found in Wood Thrushes (Vega Rivera et al. 1998). Six late-brood juvenile Ring Ouzels were subsequently located outside the study area: three to the north, two to the west, and one to the south, providing no indication that these dispersal movements represented the commencement of their southward migration. Instead, they probably reflected their need to find suitable foraging habitat (Vega Rivera et al. 1998), most likely berryrich areas (Sim et al. 2012a).

Conservation implications.-A recent demographic study indicated that the Ring Ouzel's population growth rate $(\lambda)$ was most sensitive to variation in apparent first-year survival, with most (63$68 \%$ ) estimated first-year mortality occurring in the first five weeks postfledging (Sim et al. 2011). However, this level of mortality is unlikely to be sustainable without immigration into the study area (Sim et al. 2011). Nonetheless, our juvenile Ring Ouzel survival rates were not unusually low, being similar to those of the closely related Song Thrush (Turdus philomelos), Wood Thrush, Ovenbird, and Swainson's Thrush (Catharus ustulatus; for references, see Sim et al. 2011).
Predation was the main cause of mortality for juvenile Ring Ouzels, and finding ways to reduce predation may thus be appropriate for land managers who wish to improve the conservation status of this declining upland thrush. Such measures might include providing more tall, dense, vegetation close to nests, which may decrease predation risk through the provision of cover in which juveniles can hide from predators.

\section{ACKNOWLEDGMENTS}

Supplementary material is available with the online version of this article at dx.doi.org/10.1525/auk.2012.12008. We thank Invercauld Estate for cooperation with access to Glen Clunie. S. Redpath, J. Wilson, and S. Roos provided valuable comments on the manuscript. This study was funded by the Royal Society for the Protection of Birds, Scottish Natural Heritage, and the Cairngorms National Park Authority. J.L.L. was supported by the Natural Environment Research Council.

\section{Literature Cited}

Anders, A. D., D. C. Dearborn, J. FaAborg, and F. R. ThompSON III. 1997. Juvenile survival in a population of Neotropical migrant birds. Conservation Biology 11:698-707.

Anders, A. D., J. FaAborg, and F. R. Thompson III. 1998. Postfledging dispersal, habitat use, and home-range size of juvenile Wood Thrushes. Auk 115:349-358.

Ausprey, I. J., AND A. D. Rodewald. 2011. Postfledging survivorship and habitat selection across a rural-to-urban landscape gradient. Auk 128:293-302.

Badyaev, A. V., And C. K. Ghalambor. 2001. Evolution of life histories along elevational gradients: Trade-off between parental care and fecundity. Ecology 82:2948-2960.

Berkeley, L. I., J. P. McCarty, And L. L. Wolfenbarger. 2007. Postfledging survival and movement in Dickcissels (Spiza americana): Implications for habitat management and conservation. Auk 124:396-409.

BuRfield, I. J. 2002. The breeding ecology and conservation of the Ring Ouzel Turdus torquatus in Britain. Ph.D. dissertation, University of Cambridge.

Burnham, K. P., AND D. R. Anderson. 2002. Model Selection and Multimodel Inference: A Practical Information-Theoretic Approach, 2nd ed. Springer-Verlag, New York.

Cooch, E., And G. C. White. 2008. Program MARK: "A gentle introduction." [Online.] Available at www.phidot.org/software/ mark/docs/book/.

Eaton, M. A., D. E. Balmer, R. Cuthbert, P. V. Grice, J. Hall, R. D. Hearn, C. A. Holt, A. J. Musgrove, D. G. Noble, M. PARSONS, AND Others. 2011. The State of the UK's Birds 2011. Royal Society for the Protection of Birds, Sandy, Bedfordshire.

Fisher, R. J., AND S. K. DAvis. 2011. Post-fledging dispersal, habitat use, and survival of Sprague's Pipits: Are planted grasslands a good substitute for native? Biological Conservation 144:263-271.

Gaillard, J. M., M. Festa-Bianchet, and N. G. Yoccoz. 1998. Population dynamics of large herbivores: Variable recruitment with constant adult survival. Trends in Ecology \& Evolution 13:58-63.

Genevois, F., And V. Bretagnolle. 1994. Male Blue Petrels reveal their body mass when calling. Ethology, Ecology and Evolution 6:377-383. 
Gibbons, D. [W.], S. Gates, R. E. Green, R. J. Fuller, and R. M. Fuller. 1995. Buzzards Buteo buteo and ravens Corvus corax in the uplands of Britain: Limits to distribution and abundance. Ibis 137 (Supplement 1):S75-S84.

Gibbons, D. W., J. B. Reid, and R. A. Chapman. 1993. The New Atlas of Breeding Birds in Britain and Ireland:1988-1991. T \& AD Poyser, London.

Gow, E. A., T. W. Done, And B. J. M. Stutchbury. 2011. Radiotags have no behavioral or physiological effects on a migratory songbird during breeding and molt. Journal of Field Ornithology 82:193-201.

GREEN, D. J. 2001. The influence of age on reproductive performance in the Brown Thornbill. Journal of Avian Biology 32:6-14.

Green, D. J., And A. Cockburn. 2001. Post-fledging care, philopatry and recruitment in Brown Thornbills. Journal of Animal Ecology 70:505-514.

Holmes, R. T., P. P. Marra, And T. W. Sherry. 1996. Habitatspecific demography of Breeding Black-throated Blue Warblers (Dendroica caerulescens): Implications for population dynamics. Journal of Animal Ecology 65:183-195.

Hovick, T. J., J. R. Miller, R. R. Koford, D. M. Engle, And D. M. DEBINSKI. 2011. Postfledging survival of Grasshopper Sparrows in grasslands managed with fire and grazing. Condor 113:429-437.

Kershner, E. L., J. W. Walk, and R. E. Warner. 2004. Postfledging movements and survival of juvenile Eastern Meadowlarks (Sturnella magna) in Illinois. Auk 121:1146-1154.

King, D. I., R. M. DegraAf, M.-L. SMith, AND J. P. BuOnaCCorsi. 2006. Habitat selection and habitat-specific survival of fledgling Ovenbirds (Seiurus aurocapilla). Journal of Zoology (London) 269:414-421.

Krementz, D. G., J. D. Nichols, And J. E. Hines. 1989. Postfledging survival of European Starlings. Ecology 70:646-655.

Lens, L., AND A. A. DHONDT. 1994. Effects of habitat fragmentation on the timing of Crested Tit natal dispersal. Ibis 136:147-152.

Middleton, H. A., AND D. J. GReEn. 2008. Correlates of postfledging survival, the timing of dispersal, and local recruitment in American Dippers. Canadian Journal of Zoology 86:875-881.

Morton, M. L. 1991. Postfledging dispersal of Green-tailed Towhees to a subalpine meadow. Condor 93:466-468.

Naef-Daenzer, B., F. Widmer, And M. Nuber. 2001. Differential post-fledging survival of Great and Coal tits in relation to their condition and fledging date. Journal of Animal Ecology 70:730-738.

Nur, N. 1984. The consequences of brood size for breeding Blue Tits. II. Nestling weight, offspring survival and optimal brood size. Journal of Animal Ecology 53:497-517.

Rae, L. F., G. W. Mitchell, R. A. Mauck, C. G. Gugliemo, And D. R. NorRIs. 2009. Radio transmitters do not affect the body condition of Savannah Sparrows during the fall premigratory period. Journal of Field Ornithology 80:419-426.

Schmidt, K. A., S. A. Rush, And R. S. Ostfeld. 2008. Wood thrush nest success and post-fledging survival across a temporal pulse of small mammal abundance in an oak forest. Journal of Animal Ecology 77:830-837.

Sim, I. M. W., G. W. Rebecca, S. C. Ludwig, M. C. Grant, And J. M. REID. 2011. Characterizing demographic variation and contributions to population growth rate in a declining population. Journal of Animal Ecology 80:159-170.

Sim, I. M. W., S. C. Ludwig, M. C. Grant, J. L. Loughrey, G. W. RebeCCA, AND S. ReDPATH. 2012a. Seasonal variation in foraging conditions for Ring Ouzels Turdus torquatus in upland habitats and their effects on juvenile habitat selection. Ibis 155:42-54.

Sim, I. M. W., G. W. RebecCA, AND N. I. Willinson. 2012b. Frequency of multiple brooding in Ring Ouzels, including first documented cases of triple brooding. Bird Study 59:358-362.

Sim, I. [M. W.], C. Rollie, D. Arthur, S. Benn, H. Booker, V. Fairbrother, M. Green, K. Hutchinson, S. Ludwig, M. NiCOlL, AND others. 2010. The decline of the Ring Ouzel in Britain. British Birds 103:229-239.

Smith, H. G., H. Källander, ANd J.-Å. Nilsson. 1989. The tradeoff between offspring number and quality in the Great Tit Parus major. Journal of Animal Ecology 58:383-401.

Spear, L., And N. Nur. 1994. Brood size, hatching order and hatching date: Effects on four life-history stages from hatching to recruitment in Western Gulls. Journal of Animal Ecology 63:283-298.

Sullivan, K. A. 1989. Predation and starvation: Age-specific mortality in juvenile Juncos (Junco phaenotus). Journal of Animal Ecology 58:275-286.

Thirgood, S. J., S. M. Redpath, P. J. Hudson, and E. Donnelly. 1998. Estimating the cause and rate of mortality in Red Grouse Lagopus lagopus scoticus. Wildlife Biology 4:65-71.

Tsia, K., K. H. Pollock, And C. Brownie. 1999. Effects of violation of assumptions for survival analysis methods in radiotelemetry studies. Journal of Wildlife Management 63:1369-1375.

Tucker, G. M., And M. F. Heath. 1994. Birds in Europe: Their Conservation Status. Conservation Series No. 3. BirdLife International, Cambridge, United Kingdom.

Vega Rivera, J. H., J. H. Rappole, W. J. McShea, and C. A. HAAs. 1998. Wood Thrush postfledging movements and habitat use in northern Virginia. Condor 100:69-78.

Vitz, A. C. 2008. Survivorship, habitat use, and movements for two species of mature forest birds. Ph.D. dissertation, Ohio State University, Columbus.

Vitz, A. C., And A. D. Rodewald. 2010. Movements of fledgling Ovenbirds (Seiurus aurocapilla) and Worm-eating Warblers (Helmitheros vermivorum) within and beyond the natal home range. Auk 127:364-371.

Vitz, A. C., AND A. D. Rodewald. 2011. Influence of condition and habitat use on survival of post-fledging songbirds. Condor 113:400-411.

WAtson, D. 1972. Birds of Moor and Mountain. Scottish Academic Press, Edinburgh, United Kingdom.

Wernham, C. V., M. P. Toms, J. H. Marchant, J. A. Clark, G. M. Siriwardena, ANd S. R. Baillie, Eds. 2002. The Migration Atlas: Movements of the Birds of Britain and Ireland. T \& AD Poyser, London.

White, G. C., And K. P. Burnham. 1999. Program MARK: Survival estimation from populations of marked animals. Bird Study 46 (Supplement):S120-S138.

Wiens, J. D., B. R. Noon, And R. T. Reynolds. 2006. Post-fledging survival of Northern Goshawks: The importance of prey abundance, weather, and dispersal. Ecological Applications 16:406418.

Yackel Adams, A. A., S. K. Skagen, And J. A. Savidge. 2006. Modeling post-fledging survival of Lark Buntings in response to ecological and biological factors. Ecology 87:178-188.

Associate Editor: G. R. Hepp 